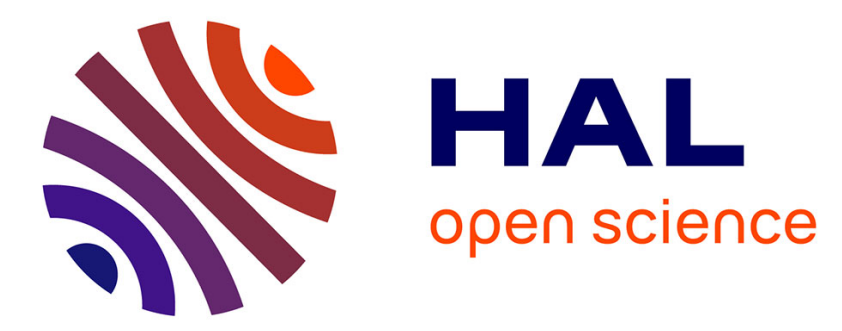

\title{
Characterization of two-dimensional Er-silicide / Si (111) interface
}

M. Tuilier, G. Gewinner, C. Pirri, P. Wetzel, D. Bolmont, O. Heckmann

\section{To cite this version:}

M. Tuilier, G. Gewinner, C. Pirri, P. Wetzel, D. Bolmont, et al.. Characterization of two-dimensional Er-silicide / Si (111) interface. Journal de Physique IV Proceedings, 1994, 04 (C9), pp.C9-187-C9-190. 10.1051/jp4:1994932 . jpa-00253493

\section{HAL Id: jpa-00253493 https://hal.science/jpa-00253493}

Submitted on 1 Jan 1994

HAL is a multi-disciplinary open access archive for the deposit and dissemination of scientific research documents, whether they are published or not. The documents may come from teaching and research institutions in France or abroad, or from public or private research centers.
L'archive ouverte pluridisciplinaire HAL, est destinée au dépôt et à la diffusion de documents scientifiques de niveau recherche, publiés ou non, émanant des établissements d'enseignement et de recherche français ou étrangers, des laboratoires publics ou privés. 


\title{
Characterization of two-dimensional Er-silicide / Si (111) interface
}

\author{
M.H. Tuilier, G. Gewinner, C. Pirri, P. Wetzel, D. Bolmont and O. Heckmann* \\ Laboratoire de Physique et de Spectroscopie Electronique, Université de Haute-Alsace, 4 rue des Frères \\ Lumière, 68093 Mulhouse cedex, France \\ * Laboratoire pour l'Utilisation du Rayonnement Electromagnétique, Centre Universitaire Paris-Sud, \\ Bâtiment 209D, 91405 Orsay cedex, France
}

\begin{abstract}
Si2p core level photoemission as well as X-ray polarization dependent surface extended absorption fine structure (SEXAFS) have been used to characterize the interface of a twodimensional erbium silicide with $\mathrm{Si}(111)$. This silicide, which consists of a hexagonal erbium monolayer located underneath a buckled Si top layer, was grown by deposition of one monolayer of erbium on clean $\mathrm{Si}(111)$ and annealing in the $400-600^{\circ} \mathrm{C}$ temperature range. Photoemission experiments reveal a Schottky barrier height $\emptyset_{\mathrm{B}}$ as low as $0.13 \pm 0.05 \mathrm{eV}$ while for thicker erbium silicide layers $\emptyset_{B}$ is found to be $\approx 0.3 \mathrm{eV}$. SEXAFS measured at the $\operatorname{Er}_{3}$ edge shows the location of erbium atoms in the eclipsed threefold hollow sites of the Si substrate.The average distance of erbium to the silicon of the substrate is found to be $3.10 \pm 0.04 \AA$, whereas the distance of erbium atoms to their three first neighbors in the Si top layer is found to be $2.94 \pm 0.04$ A.
\end{abstract}

\section{Introduction}

Atomic structure determination at the metal-semiconductor interface is of paramount importance for investigating the physics involved in the Schottky barriers formed at such contacts. As a matter of fact the screened charge transfer, which determines the observed Schottky barrier,depends on details in the interface structure [1,2]. Erbium silicide is of particular interest with respect to Schottky barrier formation studies since it forms a very low barrier with n-type $\operatorname{Si}(111)\left(\emptyset_{\mathrm{B}} \approx 0.3 \mathrm{eV}\right)$ [3]. It crystallizes in the $\mathrm{AlB}_{2}$ structure with defects in the $\mathrm{Si}$ lattice giving rise to an average composition $\mathrm{ErSi}_{2-\mathrm{x}}(\mathrm{x} \approx 0.3)$. Furthermore high crystalline quality silicide films can be grown epitaxially on $\mathrm{Si}(111)$ with $\mathrm{ErSi}_{2-\mathrm{x}}(0001)$ parallel to $\mathrm{Si}$ (111) [3-6]. A $\sqrt{3} x \sqrt{3} \mathrm{R} 30^{\circ}$ superstructure is observed and commonly attributed to ordered arrays of $\mathrm{Si}$ vacancies [5].In this paper we report on Schottky barrier height (SBH) measurements and interface structure determination of a two-dimensional (2D) erbium silicide layer epitaxially grown on n-type $\mathrm{Si}(111)$. As previously shown [7-9], this silicide layer can be prepared with a very high degree of cristallinity by annealing one $\mathrm{Er}$ monolayer deposited on $\mathrm{Si}(111)$ at room temperature and subsequently annealed in the $400-600^{\circ} \mathrm{C}$ temperature range. The $2 \mathrm{D}$ silicide exhibits a very sharp $\mathrm{p}(1 \mathrm{x} 1)$ low energy electron diffraction (LEED) pattern with a marked threefold symmetry as opposed to the $\sqrt{3} \times \sqrt{3} \mathrm{R} 30^{\circ}$ superstructure observed on thicker layers, i.e. there is no evidence of Si vacancies and related defects. Auger electron diffraction (AED) measurements $[7,8]$ have shown that the hexagonal erbium monolayer is located underneath a buckled Si top layer, similar to the double layer in bulk Si. Recently, we have performed a more refined analysis of AED data and compared the experimental data to calculated profiles by means of reliability factor analysis [10]. A more accurate determination of the interlayer spacing between Er plane and Si planes of the buckled surface double layer was achieved in this way. Best fits were obtained for interlayer spacings of 
$\mathrm{d}_{1}=1.92 \pm 0.05 \AA$ and $\mathrm{d}_{2}=2.70 \pm 0.05 \AA$. The buckling is of $0.78 \AA$ is very similar to the one observed in bulk Si.

\section{Experimental}

The Er silicide films were prepared in the same way for photoemission and SEXAFS measurements in UHV chambers equipped with Er sources, sample heating and cleaning facilities, quartz crystal microbalances and LEED optics. The Er was evaporated onto clean n-type Si (111) $7 \times 7$ at a rate of about 0.5 monolayer / $\mathrm{min}$ and a base pressure below $2.10^{-10}$ Torr. The monolayer (ML) scale is referred to the density of $\mathrm{Si}$ on the ideal $\mathrm{Si}$ (111) surface. Monochromatized AlKœ radiation was used to excite the $\mathrm{Si}$ $2 p$ core lines. The relevant electrons were analyzed with a large, $150 \mathrm{~mm}$ in radius, hemispherical energy analyser and a multichannel detector. The $\mathrm{Er} \mathrm{L}_{3}$-edge SEXAFS measurements were performed on the double-crystal monochromator of the DCI wiggler beam-line at LURE. The total electron yield was recorded while the Si(311) monochromator crystals were scanned above and below the Er-L $\mathrm{L}_{3}$ edge (8347 $\mathrm{eV})$. The $\mathrm{x}$-ray flux was monitored by measuring the photocurrent from a $\mathrm{Cu}$ grid upstream of the sample. Absorption data were collected from a channeltron at three different angles $\psi$ between the electric field of the synchrotron radiation and the normal to the sample : glancing incidence $\left(\psi=15^{\circ}\right)$, magic angle $(\psi=55$ $\left.{ }^{\circ}\right)$ and normal incidence $\left(\psi=90^{\circ}\right)$.

\section{Results and discussion}

Figure 1 shows the Si $2 p$ core levels measured at normal photoelectron emission using a monochromatized AlK $\propto$ line (h $\omega=1486.6 \mathrm{eV}$ ) on several Er silicides achieved by annealing at $500^{\circ} \mathrm{C} \mathrm{Er}$ deposits in the $0-2 \mathrm{ML}$ range. Also shown on fig. 1 is the Si $2 p$ spectrum measured on clean $\mathrm{Si}(111) 7 \times 7$ surface. The LEED pattern is $p(1 \times 1)$ in the monolayer range and $\sqrt{ } 3 x \sqrt{3} R 30^{\circ}$ for the 2 $\mathrm{ML}$ deposit. The Si $2 \mathrm{p}$ spectra in this coverage range are dominated by strong substrate emission at high binding energy. A small contribution of the silicide $\mathrm{Si}$ atoms is observed, shifted by about 0.5 $\mathrm{eV}$ towards lower binding energies, due to charge transfert from $\mathrm{Er}$ atoms to Si [11]. The substrate contribution to the Si $2 p$ spectra moves towards higher binding energies in the $0-1 \mathrm{ML}$ range. The largest binding energy shift is measured for $1 \mathrm{ML}$ and is about 0.34 $\mathrm{eV}$. For higher coverages this substrate related component shift is reduced and amounts at about $0.18 \mathrm{eV}$, which is the value measured for thicker silicide layers grown on n-type $\mathrm{Si}(111)$ [12], even for coverages as low as $2 \mathrm{ML}$. Change in $\mathrm{Si} 2 \mathrm{p}$ binding energy reflects change in the Fermi level pinning position when the silicide-silicon interface is formed. By measuring the Si $2 \mathrm{p}$ core level shift with respect to clean $\mathrm{Si}(111) 7 \times 7$ surface one can estimate the $\mathrm{SBH} \emptyset_{\mathrm{B}}$ for these coverages. The $\mathrm{Si}(111) 7 \times 7$ surface has a metallic character in which the Fermi level is stable at $0.65 \mathrm{eV}$ above the valence band maximum and thus the substate component for this surface reconstruction can be used as reference [13]. Taking account for a

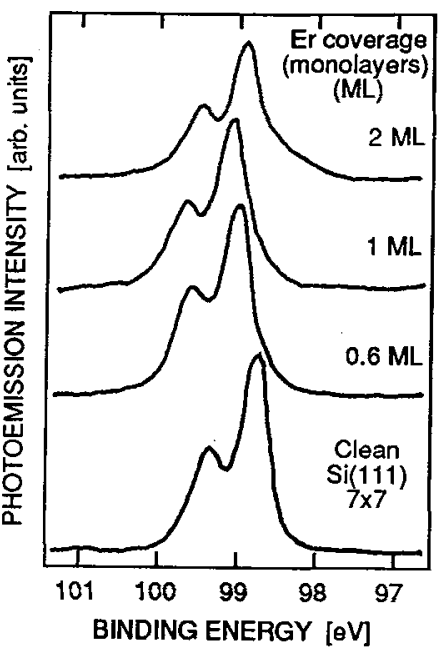

Fig.1. Si 2p spectra as a function of Er coverage value of the Si gap of $1.12 \mathrm{eV}$ we found a SBH $\emptyset_{\mathrm{B}}=0.29 \pm 0.05 \mathrm{eV}$ for thick silicide layers ( above $2 \mathrm{Er}$ monolayers) in agreement with values found in the litterature $[3,5,12]$. The SBH decreases down to a value $\emptyset_{\mathrm{B}}=0.13 \pm 0.05 \mathrm{eV}$ for the 2D Er silicide.

The raw $k \chi(k) E_{3} L_{3}$ SEXAFS data recorded for (a and d) $1 \mathrm{ML}$, (b and e) 2 ML erbium deposits onto $\mathrm{Si}(111)$ annealed at $500^{\circ} \mathrm{C}$ and (c and $\mathrm{f}$ ) a thick silicide layer (60 ML) (from ref.14) are presented in fig. 2 at normal and glancing incidence respectively. The data are shown after background substraction and conversion to k-space together with their first shell Fourier filtered contribution [15]. The spectra of the 2D Er disilicide layer (2-a) and (2-d) are very singular and exhibit a strong polarization dependence whereas the data from the $2 \mathrm{ML}$ Er silicide (2-b) and (2-e) are close to those coming from the thick sample (2-c) and (2- 


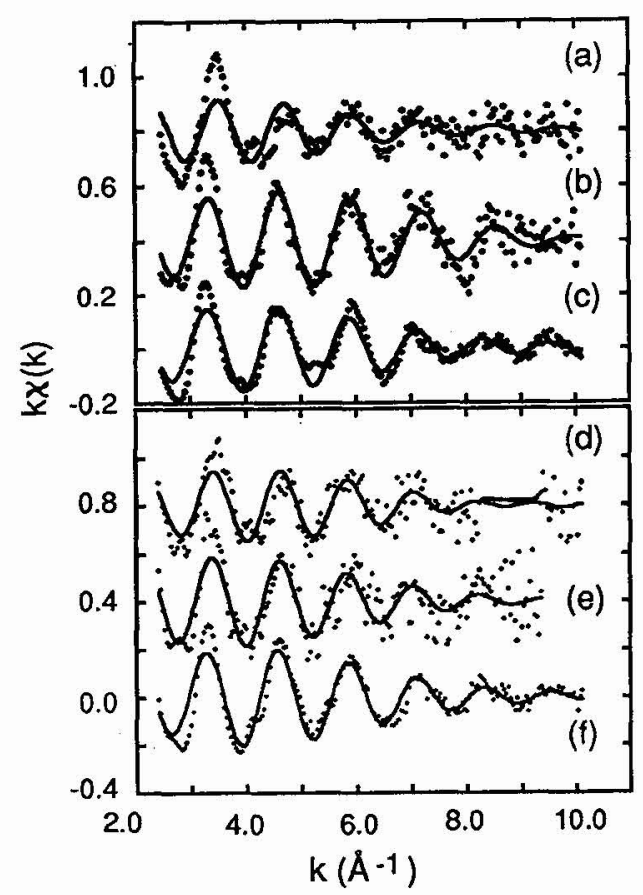

Fig.2. Raw k-weighted data (dots) recorded from: $1 \mathrm{ML} \operatorname{Er}$ ( $\mathrm{a}$ and d), $2 \mathrm{ML} \mathrm{Er}$ ( $\mathrm{b}$ and $\mathrm{e}$ ) and $60 \mathrm{ML} \mathrm{Er}(\mathrm{c}$ and $\mathrm{f})$ silicides in normal $\left(\psi=90^{\circ}\right)$ and glancing incidences $\left(\psi=15^{\circ}\right)$ respectively. The data are plotted with their filtered first shell contribution.

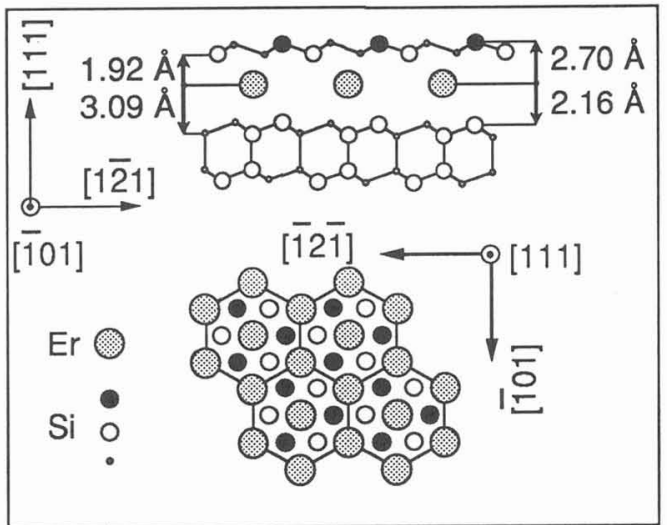

Fig.3. Top and side views of the $\mathrm{T}_{4}$ atomic geometry at the interface.

f). The complete EXAFS analysis of $\mathrm{ErSi}_{2-\mathrm{x}}$ grown epitaxially on $\mathrm{Si}$ (111) is described elsewhere [14]. Let us examine the geometry of the 2D Er disilicide layer. The surface arrangement deduced from AED measurements $[7,8,10]$ is a buckled $S i$ top layer with interlayer spacing $d_{1}=1.92 \pm 0.05 \AA$ and $\mathrm{d}_{2}=2.70 \pm 0.05 \AA$ (as shown in fig. 3). The Er-Si bond lengths deduced from this geometry are $2.93 \pm 0.05 \AA$ and $3.50 \pm 0.05 \AA$ respectively. Only the three silicon atoms lying at the shorter distance contribute to the first neighbors shell. Below the erbium atomic plane, four interfacial geometries may be considered, namely $\mathrm{H}_{3}, \mathrm{~S}, \mathrm{~T}$ and $\mathrm{T}_{4}$. In $\mathrm{H}_{3}$ and $\mathrm{T}_{4}$ geometries Er $\propto$ ccupies respectively threefold and eclipsed threefold hollow sites of the Si (111) substrate termination. The $S(T)$ sites are substitutional (top) sites where the Er replaces (is located just above) the Si atoms in the top layer of the substrate. In $\mathrm{H}_{3}$ and $\mathrm{S}$ geometries the erbium atoms have a similar first coordination shell with three nearest $S i$ neighbors in the substrate. The difference between the $\mathrm{H}_{3}$ and $\mathrm{S}$ sites only shows up in the second coordination shells. Erbium placed in $\mathrm{T}$ and $\mathrm{T}_{4}$ sites has one and four Si neighbours in the substrate, respectively. The simulation of the Fourier filtered first shell SEXAFS data at the normal, magic and glancing angles gives values of $2.98 \AA, 2.99 \AA$ and 3.04 $\AA$ respectively, showing that the average Er-Si bond length $R_{\mathrm{Er}-\mathrm{Si}}$ increases as $\psi$ decreases. This evolution is quite inconsistent with the roughly isotropic Si neighbours contribution expected for $\mathrm{H}_{3}$ or $\mathrm{S}$ geometries. In contrast it is the expected behavior in $\mathrm{T}$ and $\mathrm{T}_{4}$ models where the Er occupies atop positions of the Si substrate with Er-Si bonds along the surface normal that contribute strongly to the EXAFS signal when the electric field vector has a sizeable projection along the surface normal.

The bonding geometry was firmly established when we considered a better model of the SEXAFS analysis that assumes a two component fit with dual near-neighbor bond lengths. In this refined analysis the Fourier filtered first shell recorded at normal incidence is fairly well accounted for by two Er-Si distances of 2.94 and $3.10 \AA$ respectively. The first one is attributed to the silicon neighbors of Er in the $\mathrm{Si}$ 
top layer, in excellent agreement with AED results. The second one is assigned to the silicon neighbors at the interface with the substrate.The expected effective coordination numbers $N_{i}^{*}$ are first calculated [16] with a structure that corresponds to the $\mathrm{d}_{1}$ and $\mathrm{d}_{2}$ values deduced from $A E D$ and an Er-Si distance of $3.10 \AA$ at the interface. These values of $\mathrm{N}^{*}$, which are summarized in table 1 for all of the investigated models, are then used as initial parameters in the simulations. As can be seen in table 1 the results of these refinements for both normal and grazing incidence data are in good agreement with a $\mathrm{T}_{4}$ geometry, with four silicon neighbours at $3.10 \pm 0.04 \AA$ below the erbium atoms. This analysis shows that the same Er-Si near neighbor distance is found to the first and second layer Si atoms of the substrate. The buckling of the $\mathrm{Si}(111)$ double layer at the substrate- silicide is thus increased by about $0.15 \AA$ with respect to bulk $\mathrm{Si}$. This relaxation gives more s character to the substrate Si dangling bonds which are thought to pin the Fermi level after interaction with the silicide and may favor a large transfert from Er to Si [1]. This could explain the very low SBH observed in the photoemission experiments (a detailed discussion of these effects can be found in ref.10).

\section{Summary}

Upon specific preparation conditions a two-dimensional erbium silicide with a very high degree of crystallinity can be grown on $\mathrm{Si}(111)$. The erbium silicide-silicon interface has been characterized by $\mathrm{Si} 2 \mathrm{p}$ core level measurements showing a SBH as low as $0.13 \mathrm{eV}$. The interface atomic structure has been determined by polarization dependent SEXAFS measurements and it was found that Er atoms sit in eclipsed threefold hollow sites $\left(\mathrm{T}_{4}\right)$ of the substrate termination .

\section{References}

[1] Lannoo M. and Friedel P., in "Atomic and Electronic Structure of Surfaces", Theoretical Foundations, Springer Verlag, Berlin (1991)

[2] Mönch W., in "Semiconductor Surfaces and Interfaces", Springer Verlag, Berlin (1993)

[3] Tu K.N.,Thompson R.D. and Tsaur B.Y., Appl.Phys.Lett.38, 626 (1981)

[4] Knapp J.A., Picraux S.T., Appl.Phys.Lett.4 8, 466 (1986)

[5] d'Avitaya F.A. , Perio A., Oberlin J.C., Campidelli Y., Chroboczek J.H., Appl.Phys.Lett.54, 2198 (1989)

[6] Kaatz F.H., Siegal M.P., Graham W.R., Van der Spiegel J. and Santiago J.J., Thin Solid Films 184, 325 (1990)

[7] Paki P., Kafader U., Wetzel P., Pirri C., Peruchetti J.C., Bolmont D. and Gewinner G., Phys.Rev. B 45, 8490 (1992)

[8] Wetzel P., Pirri C., Paki P., Bolmont D. and Gewinner G., Phys.Rev. B47, 3677 (1993)

[9] Wetzel P., Pirri C., Paki P., Peruchetti J.C., Bolmont D. and Gewinner G., Solid State Commun. 82, 235 (1992)

[10] Tuilier M.H., .Wetzel P., Pirri C., Bolmont D. and Gewinner G., submitted to Phys.Rev.B. (1994)

[11] Wetzel P., Haderbache L., Pirri C., Peruchetti J.C., Bolmont D. and Gewinner G., Phys. Rev. B 43, 6620 (1991)

[12] Veuillen J.Y., Lollman D.B.B., Nguyen Tan T.A., Magaud L., Appl.Surf.Sci.65/65, 712 (1993)

[13] Himpsel F.J., Meyerson B.S., Mc Feely F.R., Morar F.J., Thaleb-Ibrahimi A. and Yarmoff J.A., in Proceeding of the International School of Physics Enrico Fermi, edited by M.Campagna and R.Rosei (North Holland, 1990) and references cited therein

[14] Tuilier M.H., Pirri C., Wetzel P., Gewinner G., Veuillen J.Y., Nguyen Tan T.A.,European Conference on Surface Science,ECOSS 13, Warwick (UK), 1993 and tobe published in Appl. Surf. Sci.

[15] Michalovicz A., in "Logiciels pour la Chimie" (Société Française de Chimie, Paris, 1991), p.402.

[16] Stöhr J., in "X-ray Absorption : Principles, Applications and Techniques of EXAFS, SEXAFS and XANES“, edited by D.C. Koningsberger and R. Prins (Wiley, New York, 1988), p. 443. 